\title{
CORRECTION
}

\section{Correction to: Suicidal Mental Imagery in Psychiatrically Hospitalized Adolescents}

\author{
Hannah R. Lawrence ${ }^{1}$. Jacqueline Nesi ${ }^{2,3} \cdot$ Taylor A. Burke ${ }^{3,3} \cdot$ Richard T. Liu $^{4}$ - Anthony Spirito ${ }^{2}$. Jeffrey Hunt ${ }^{2,3}$. \\ Jennifer C. Wolff' ${ }^{2,3}$
}

Published online: 27 May 2021

(c) Springer Science+Business Media, LLC, part of Springer Nature 2021

\section{Correction to: Research on Child and Adolescent Psychopathology (2021) 49:393-399 https://doi.org/10.1007/s10802-020-00750-4}

The original version of this article unfortunately contained a mistake. We notice an error in the 2nd author's first name which is misspelled (Jaqueline should be Jacqueline). The original article has been corrected.
Publisher's Note Springer Nature remains neutral with regard to jurisdictional claims in published maps and institutional affiliations.

The original article can be found online at https://doi.org/10.1007/ s10802-020-00750-4.

Hannah R. Lawrence

hannah.r.lawrence@maine.edu

1 Department of Psychiatry, McLean Hospital/Harvard Medical School, Boston, USA

2 Department of Psychiatry \& Human Behavior, Division of Clinical Psychology, Brown Universit, Providence, USA

3 Bradley/Hasbro Research Center, Rhode Island Hospital, Providence, USA

4 Department of Psychiatry, Massachusetts General Hospital, Boston, USA 